\section{AB1077 DOES PRECONSULT ELECTRONIC EXCHANGE AFFECT POSTCONSULT DIAGNOSIS?}

G. Miller ${ }^{1}$, B. Chou ${ }^{1}$, N. Patel ${ }^{2}$, G. Karpouzas ${ }^{1} .{ }^{1}$ Division of Rheumatology; ${ }^{2}$ Department of Internal Medicine, Harbor UCLA Medical Center, Torrance, CA, United States

Background: Harbor UCLA is an urban safety-net hospital in Los Angeles for underserved patients. In 2014, LA County Department of Health Services adopted an electronic consultation (E-consult) referral and dialogue system to improve access to subspecialists in the ambulatory care setting. The E-Consult system provides a platform for primary care providers to ask questions or engage in dialogue with specialists, request consultation, and track submitted requests. Back and forth messaging prior to acceptance for face-to-face consultation is termed a "preconsult exchange".

Prior studies of E-Consult systems have suggested benefits which include a reduction in wait times compared to paper referrals ${ }^{1}$ and a perceived improvement in patient care ${ }^{2}$. We sought to further clarify the effect of a preconsult exchange versus immediate booking on a patient's diagnosis and wait time in an effort to provide some guidance on whether E-Consult should be used as a screening tool to reduce unnecessary visits or as a communication method to clarify details before a face-to-face visit.

Objectives: To determine whether preconsult exchange:

1. Influences the odds of arriving at a different diagnosis after face-to-face consultation compared to the requesting provider's original diagnosis

2. Influences the odds of arriving at a diagnosis of a different autoimmune condition versus a non-autoimmune condition (fibromyalgia, primary osteoarthritis, chronic pain, or other non-rheumatologic condition)

3. Results in a significant delay in face-to-face evaluation

Methods: We performed a retrospective chart review of all 238 new patient referrals between 11/2014 and 5/2016 to the Harbor UCLA Rheumatology clinic generated through the E-Consult system, reviewed by BC or GM, deemed appropriate, and seen for face-to-face evaluation. These patients were grouped by exposure (Preconsult exchange or not). Odds of change in diagnosis and confidence intervals were calculated using $2 \times 2$ contingency tables and Chi-Square tests. A student's $T$ test was used to compare mean number of days between E-Consult initiation and face-to-face appointment.

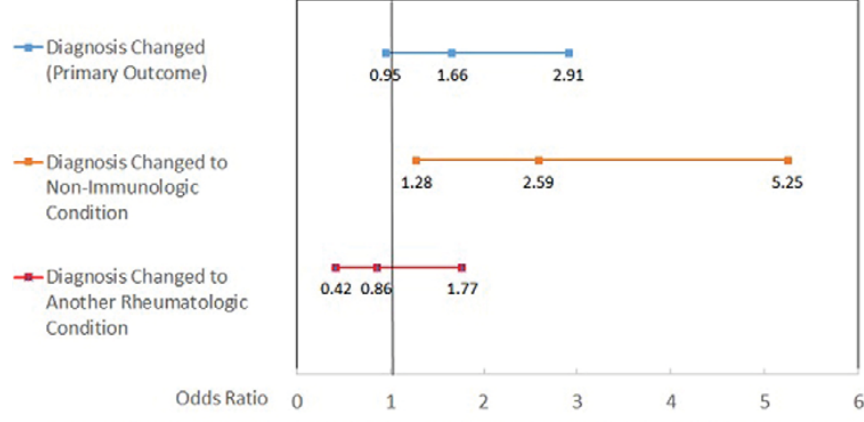

Figure 1. Odds of Change in Diagnosis Following a Preconsult Exchange

Conclusions: There was a trend towards a change in diagnosis overall among patients for whom there was a preconsult exchange, but a statistically significant increase in odds for change to non-immunologic diagnoses. This suggests that preconsult exchange highlights those patients for whom there is a higher likelihood of a non-immunologic diagnosis.

However, preconsult exchange was associated with a significant time cost an additional 26 day delay for a face-to-face visit (due to the time needed for both submitter and reviewer to complete their dialogue) in comparison to an immediately booked patient.

\section{References:}

[1] Chen A et al. A Safety-Net System Gains Efficiencies Through 'eReferrals' To Specialists. Health Affairs 29, no.5 (2010):969-971.

[2] Scheibe MM et al. Efficiency Gains for Rheumatology Consultation Using a Novel Electronic Referral System in a Safety-Net Health Setting. Arthritis Care Res (Hoboken). 2015 Aug;67(8):1158-63.

Disclosure of Interest: None declared

DOI: 10.1136/annrheumdis-2017-eular.5581

\section{AB1078 IMPACT OF PRE-SCREENING ON RHEUMATOLOGY OUTPATIENT CLINIC PRACTICE}

C. Orr, O. McElvaney, M. McQuillan, M. Hussein, S. Donnelly, G. McCarthy, C. McCarthy. Rheumatology, Mater Misericordiae University Hospital, Dublin, Ireland

Background: Chronic rheumatological diseases are predominantly managed in an outpatient setting, and these out patient clinics constitute a significant workload for rheumatolgy clinicicians. When unnecessary outpatient visits occur, service provision to those most in need of rheumatology review, both new referrals and those with established diagnoses in need of urgent review, is compromised. There is an evidence base for such screening in secondary care centres from other internal medicine disciplines (1).

Objectives: To determine the impact of introducing pre-clinic screening, and exploring the potential for follow up using telephone, by a physician extender (PE), on attendances at a rheumatology outpatient department.

Methods: A retrospective chart review of all patients attending a rheumatology outpatient clinic was performed over a 4-week period, 15/08/2016- 09/09/2016. Patients were categorized into new or follow-up attendees and the follow-up patients were further subcategorized into 1 of 4 groups:

A) Attending to receive results of investigations requiring no further treatment;

B) Attending with a chronic rheumatological disease requiring no active change in management;

C) Attending to receive results of investigations requiring further treatment;

D) Attending with a chronic rheumatological disease requiring active change in management.

Patients in categories A and B, may be safely managed by a phone call from a physician, or PE. Those in C and D would need to be reviewed in clinic, following triage by phone using a PE.

Results: 232 subjects were included ( 5 category A, 118 category B, 4 category C, 105 category D). $123(53.0 \%$ ) could be managed by phone utilizing a PE, thus obviating the need for review in clinic. The remaining patients could be triaged by telephone by a PE, and the schedule for review adjusted to prioritise those most in need of review. It is likely that such a strategy for reviewing patients would be more clinically efficient, have a greater impact on patient well-being, and be cost-saving. Conclusions: Routine pre-screening for patients attending rheumatology clinics should be considered to improve effectiveness of the commodity rheumatology expertise.

References:

[1] Donnellan, F., Harewood, G.C., Cagney, D., Basri, F., Patchett, S.E. and Murray, F.E., 2010. Economic impact of prescreening on gastroenterology outpatient clinic practice. Journal of clinical gastroenterology, 44(4), pp.e76-e79.

Disclosure of Interest: None declared

DOI: 10.1136/annrheumdis-2017-eular.6893

\section{AB1079 FOLLOW UP OF PATIENTS WITH RHEUMATIC DISEASES BY MEANS OF A SMARTPHONE APPLICATION: SATISFACTION INDEX BASED ON A SURVEY AMONG USERS AND CARE PROVIDERS}

C.A. Guillen-Astete ${ }^{1}$, J.L. Alba-Barton ${ }^{2}{ }^{1}{ }^{1}$ Rheumatology Department, Ramon y Cajal University Hospital, Madrid, Spain; ${ }^{2}$ Informatics, Surveys and Stata, Lima, Peru

Background: Therapeutic adherence is the main variable in order to assess success or failure of any treatment. It is matter of interest to any clinician to get information enough about treatment response along time to reach a better understanding of any factor that conditions adherence failure or treatment interruptions. However, this kind of information is quite difficult to obtain in real scenarios due to lack of time or memory issues.

Objectives: The aim of present study is to assess the opinion of users of a smartphone application developed to improve the follow up of patients with different rheumatic diseases.

Methods: We conducted a survey to the users of REUMapp, an electronic form based on Google Form ${ }^{\circledR}$ software. REUMapp is an electronic interactive form developed for four different clinical scenarios: REUMapp-Esp (spondyloarthritis), REUMapp-Cristal (gout and othe microcrystalline arthropathies), REUMappAR (Rheumatoid arthritis) and REUMapp-MSK (soft tissues). All forms were developed over the basis of paper forms previously used for the same purposes and to be checked on follow up consultation. Forms were designed to gather information about daily treatment adherence (binomial), daily modifications (categorical), adverse effects (categorical) and therapeutic response in terms of visual analogical scale. REUMapp-ESP and REUMapp-AR include also specific joint recounts and indexes. All the forms could be completed in less than 3 minutes by the patient or his/her care provider. Every form contents became part of a database easily accessible during the follow up visit in a summarized way. Between 2014-2016, 419 apps were installed in patients or care provider's smartphones from two non public rheumatology clinics of Madrid with fully consentient of them. A survey was send to every user at the third to twelfth month after installation who have had one follow up consultation at least and who previously used the paper forms. Survey was developed using a multiple answer scheme using visual 7-level horizontal Likert scales. Topics of the survey were as follows: simplicity, time consumption and usefulness. Surveyed patients also were asked for the usefulness of the paper-based form.

Results: 205 Patients or care providers answered the survey. From them, 36 patients had diagnosed by rheumatoid arthritis, 23 by spondyloarthritis, 68 by gout or other microcrystalline arthritis and the rest by any other soft tissue rheumatisms. Following table shows the results of the survey. In the non parametric analysis of usefulness, the app was considered more useful than the paper format with a wilcoxon coefficient of contrast for paired data of $-6.6589(p<0.0001)$.

Conclusions: The smartphone applications described in this study have a good acceptance among patients of care providers in terms of usefulness, time consumption and simplicity and they are considered more useful than the printed models. 


\begin{tabular}{|c|c|c|c|c|c|c|c|}
\hline & Mean & Median & Mode & Variance & $\begin{array}{l}\text { Standard } \\
\text { deviation }\end{array}$ & $\begin{array}{c}\text { Interquartile } \\
\text { range }\end{array}$ & $\begin{array}{l}\text { Curtosis } \\
\text { (STD) }\end{array}$ \\
\hline $\begin{array}{l}\text { SIMPLICITY } \\
\text { (1: Too difficult; } 7 \text { : Very }\end{array}$ & 5.4927 & 5.0 & 7.0 & 2.2610 & 1.5037 & ronge & 0.8358 \\
\hline * The user is the patient & 5.3453 & 5.0 & 6.0 & & & & \\
\hline $\begin{array}{l}\text { * The user is the care } \\
\text { provider }\end{array}$ & 5.5564 & 5.0 & 7.0 & & & & \\
\hline $\begin{array}{l}\text { *The user is the patient } \\
\text { and the care provider. }\end{array}$ & 5.6648 & 5.0 & 6.0 & & & & \\
\hline $\begin{array}{l}\text { TIME CONSUMPTION } \\
\text { (1: Not significant ; } 7 \text { : Too } \\
\text { much) }\end{array}$ & 3.4341 & 3.0 & 3.0 & 2.5911 & 1.6176 & 2.0 & 0.0678 \\
\hline $\begin{array}{l}\text { USEFULNESS (1: None; } 7 \text { : } \\
\text { Very useful). }\end{array}$ & 5.4585 & 6.0 & 7.0 & 2.1319 & 1.4601 & 2.0 & 1.5696 \\
\hline $\begin{array}{l}\text { USEFULNESS OF THE } \\
\text { PAPER MODEL (1: None; } \\
\text { 7: Very useful). }\end{array}$ & 4.3902 & 5.0 & 5.0 & 3.5626 & 1.8875 & 3.0 & -0.9363 \\
\hline
\end{tabular}

Disclosure of Interest: None declared

DOI: 10.1136/annrheumdis-2017-eular.5182

\section{AB1080 RESULTS IN THE FOLLOW-UP OF THE NURSING CONSULTATION FOR THE MONITORING OF RHEUMATOLOGIC PATIENTS TREATED WITH INTRAVENOUS THERAPIES}

C. Nájera Herranz ${ }^{1}$, I. Cánovas OImos ${ }^{1}$, J. Ivorra Cortes ${ }^{1}$, E. Grau Garcia ${ }^{1}$, C. Alcañiz Escandell ${ }^{1}$, K. Arévalo Ruales ${ }^{1}$, I. Chalmeta Verdejo ${ }^{1}$, C.M. Feced Olmos $^{1}$, J.J. Fragio Gil ${ }^{1}$, R. González Mazarío ${ }^{1}$, L. Gonzalez Puig ${ }^{1}$, E. Labrador Sánchez ${ }^{1}$, I. Martínez Cordellat ${ }^{1}$, R. Negueroles Albuixech ${ }^{1}$, J.E. Oller Rodriguez ${ }^{1}$, F.M. Ortiz-Sanjuan ${ }^{1}$, E. Vicens Bernabeu ${ }^{1}$, D. Hervás Marín ${ }^{2}$, J.A. Román Ivorra ${ }^{1} .{ }^{1}$ Rheumatology Department, HUP la Fe; ${ }^{2}$ Biostatistics Unit, IIS la Fe, Valencia, Spain

Background: In the management of rheumatologic patients treated with intravenous therapies, its regular monitoring is recommended in order to ensure its safety. The Nursing Consultation for monitoring rheumatologic patients treated with Intravenous Therapies (NCIT) represents a major support to patient caring for it provides patient monitoring before treatment administration and prior to rheumatologist consultation.

Objectives: To analyze number and types of incidents detected in the NCIT.

Methods: A cross-sectional longitudinal, observational study of data from patients followed-up in the NCIT (which was initiated in 2012) was performed. We have collected data of gender, diagnosis, drug administered, incidents detected previously to the drug administration, and if the incident was detected by telephone (one day before drug administration) or by personal interview. Biostatistical analysis with $\mathrm{R}$ (3.3.2.) was performed.

Results: We analyzed 7809 drug infusions corresponding to 545 patients $(73 \%$ women). $48.25 \%$ of patients were diagnosed with osteoporosis (OP), $30.1 \%$ rheumatoid arthritis (RA), $5.7 \%$ ankylosing spondylitis (AS), $4.2 \%$ systemic lupus erythematous (SLE), 2.9\% psoriatic arthritis (PsOA) and $8.3 \%$ had other diagnosis. The intravenous therapies were antiosteoporotic drug $(7.8 \%)$ and biological and immunosuppressive treatment, being the most common drugs tocilizumab (38.89\%), infliximab (31.9\%) and abatacept (18.05\%). In the 7809 treatment infusions, 477 incidents $(4.1 \%)$ were registered, 33 of them related to the antiosteoporotic therapies and the other 444 incidents (93\%) occurred in the biological therapies. The $63.7 \%$ of the incidents were detected by telephone one day before drug infusion. Statistical analysis showed that SLE patients exhibit higher tendency to incidents $(4.8 \%$ of incidents in the 392 treatments for SLE patients; $P=0.026)$ than other autoimmune diseases. On the other hand, RA and AS patients have incidents detected mainly by telephone ( $P=0.047$ y $P=0.029$ respectively). We also observed a high number of incidents in the intravenous administration of TCZ ( $P=0.009)$.

Conclusions: The NCIT has performed the follow-up of more than 500 patients with only $6 \%$ of incidents, contributing to an improvement in the patients' health and in its caring. Moreover, the fact of identifying the incidents helps to reduce the number of personal consultations, avoids drug preparation in those cases where this infusion is suspended, and in summary it improves management of hospital resources.

Disclosure of Interest: None declared

DOI: 10.1136/annrheumdis-2017-eular.5702

\section{AB1081 INTEGRATING CASE FINDING AND INITIAL MANAGEMENT FOR OSTEOARTHRITIS, ANXIETY AND DEPRESSION INTO ROUTINE PRIMARY CARE NURSE-LED LONG-TERM CONDITION REVIEWS: RESULTS FROM THE ENHANCE PILOT TRIAL}

C. Jinks ${ }^{1}$, E. Nicholls ${ }^{1,2}$, J. Liddle ${ }^{1}$, E.L. Healey ${ }^{1}$, A.L. Evans ${ }^{1}$, C.A. Chew-Graham ${ }^{1}$, K.S. Dziedzic ${ }^{1}$, V.A. Tan ${ }^{1}$, A.G. Finney ${ }^{1}$, M. Porcheret ${ }^{1}$ S. Lawton ${ }^{2}$, V. Cooper ${ }^{1}$, M. Lewis ${ }^{1,2}$, C.D. Mallen ${ }^{1}$ on behalf of ENHANCE team. ${ }^{1}$ Research Institute for Primary Care \& Health Sciences; ${ }^{2}$ Keele Clinical Trials Unit, Keele University, Keele, United Kingdom

Background: Co-morbid osteoarthritis (OA), anxiety and depression are undermanaged in primary care yet have significant impact on pain, disability and outcomes of other long-term conditions (LTCs).

Objectives: To test the feasibility and acceptability of integrating case-finding and initial management for $\mathrm{OA}$, anxiety and depression within extended primary care practice nurse (PN)-led LTC review consultations.
Methods: A stepped wedge pilot trial with process evaluation. PNs gave a study pack to patients age $\geq 45$ years attending routine LTC reviews (asthma, COPD, hypertension, ischaemic heart disease, diabetes). The intervention included case finding questions (Generalized Anxiety Disorder (GAD2), Whooley 2-item depression, diagnosing OA clinically (hands, hips, knees or feet)) followed by further assessments (anxiety (GAD7), depression (PHQ9), joint examination). PNs completed an electronic patient record and initiated management. Predetermined success criteria were to recruit 4 practices; deliver training to 2 PNs per practice, recruit $50 \%$ of those invited, ensure $75 \%$ follow up (6 week, 6 month), and the satisfaction (GPAQ) of intervention patients to be at least as acceptable as that of control patients. 24 audio recorded consultations provided insight into fidelity of intervention delivery.

Results: Four practices were recruited. PNs were sequentially trained in practice prior to switching to intervention. Of the 474 people invited, 319 responded (207 control, 112 intervention) (67\%). $83 \%$ and $79 \%$ of participants returned 6 week and 6 month questionnaires respectively. Demographic characteristics, general health, pain intensity, anxiety and depression scores were similar across arms. Overall, self-reported health (EQ5D5L) was high (median 0.84; IQR 0.72, 0.94). $14 \%$ of participants reported moderate to severe depression (PHQ9). Median GPAQ scores were similar (control 1.00 (IQR: 1.00, 1.29), intervention 1.00 (IQR: $1.00,1.14)) .96 \%$ of those in the intervention arm reported being asked about joint pain, $93 \%$ reported being asked about mood. Audio recordings revealed that case finding questions were used as intended in most consultations (joint pain 20/24 consultations, anxiety 15/24, depression 6/24). One referral to physiotherapy and none to primary care mental health services were recorded by the PNs.

Conclusions: Recruitment and follow up were good. However, to target those who may benefit from the intervention, changes to the target population and eligibility criteria are required. There was reasonable delivery of the case finding questions, but limited referral and signposting, highlighting areas to optimise ahead of a main trial.

Acknowledgements: ELH, CJ, CCG, ALE and CDM are part funded by NIHR Collaborations for Leadership in Applied Health Research and Care West Midlands. CDM is funded by NIHR School for Primary Care Research, NIHR Research Professorship in General Practice (NIHR-RP-2014-04-026). KSD is part-funded by an NIHR Knowledge Mobilisation Research Fellowship (KMRF2014-03-002). Views expressed in this paper are those of the author(s) and not necessarily those of the NHS, the NIHR, or the Department of Health.

Disclosure of Interest: None declared

DOI: 10.1136/annrheumdis-2017-eular.2473

\section{AB1082 IMPACT OF ANKYLOSING SPONDYLITIS VERSUS NON-RADIOGRAPHIC SPONDYLOARTHRITIS ON EARLY RETIREMENT}

C. Cobilinschi, R. Ionescu, D. Opris-Belinski. Sfanta Maria Clinical Hospital, Bucharest, Romania

Background: Axial spondyloarthritis include non-radiographic SpA (nr-SpA) and ankylosing spondylitis (AS), suggesting the extent of sacroiliac involvement on imaging techniques (1). The influence of the two conditions on patients' physical function and their impact on work capacity should be regularly assessed so that we can better contribute to patients' social integration.

Objectives: The present study aims to assess the differences between AS and $\mathrm{nr}-\mathrm{SpA}$ patients under anti-TNF therapy regarding disease related retirement (DR) and its contributing factors.

Methods: Over a period of eleven months 136 patients diagnosed with AS or nr-SpA on current biological therapy were included. Demographic data and working status were assessed. Statistical analysis was performed with SPSS 20.0.

Results: In the study cohort $69 \%$ of patients were males. The predominant age group was situated between 30 to 40 years old $(29.8 \%)$, while $20.2 \%$ were over 50 . Out of the study group, $66 \%$ confirm they are active in their work field with a minimum of seven hours per day, whereas $4.3 \%$ reached their retirement age. $29.8 \%$ of patients were granted a disability retirement and the majority $(42.9 \%)$ belonged to the $40-50$ age group. Surprisingly, $6.8 \%$ of early retired patients were under 30 . Out of the DR category, $92.9 \%$ were diagnosed with AS, while the rest of $7.1 \%$ had $\mathrm{nr}-\mathrm{SpA}$. The interval from diagnosis to the initiation of biological therapy was $72.5 \pm 85.1$ months for AS patients and $64.1 \pm 71.2$ for nr-SpA. $23.2 \%$ of patients applied for early retirement before biological therapy and only $3.1 \%$ resumed work after anti-TNF introduction. Patient gender did not influence the working capacity. At the time of study inclusion, $12 \%$ of patients with AS and $4 \%$ of patients with nr-SpA still exhibited signs of highly active disease, according to ASDAS-CRP assessment.

Conclusions: Almost a third of patients in the study group were offered early retirement due to axial $\mathrm{SpA}$. The vast majority of disease related retirement patients were known with AS, thus emphasizing the extent of disability brought on by this entity. However, a significant percentage of patients suffered from $\mathrm{nr}-\mathrm{SpA}$, raising doubts as to whether clinicians can promptly diagnose this entity and offer early, appropriate treatment so that inability no longer occurs.

\section{References:}

[1] Wendling D, Prati C, Claudepierre P, Guillot X, Breban M. Non-radiographic spondyloarthritis: A theoretical concept or a real entity? Jt Bone Spine. 2012. Disclosure of Interest: None declared 